\title{
ERC
}

\section{Remote Recession Sensing of Ablative Heat Shield Materials}

Michael Winter, University of Kentucky, KY

Margaret Stackpoole, NASA Ames Research Center, Moffett Field, CA

Anuscheh Nawaz, Sierra Lobo, Inc., NASA Ames Research Center, Moffett Field, CA Gregory Lewis Gonzales, ERC, Inc., NASA Ames Research Center, Moffett Field, CA Thanh Ho, Universities Space Research Association (USRA), NASA Ames Research Center, Moffett Field, CA

6th Ablation Workshop

April 10-11 2014, University of Illinois at Urbana-Champaign

\section{Acknowledgments:}

- NASA Contract NNA10DE12C to ERC, Inc.

Thanks to George Raiche (Chief, Thermophysics Facilities Branch, NASA ARC), Dean Kontinos (Chief, Entry Systems \& Technology Division, NASA ARC), Ethiraj Venkatapathy, Jim Arnold, Jay Grinstead, Dinesh Parabhu (ERC, Inc.), and the arc jet operation crew. 


\section{ERC}

\section{Remote Recession Sensing of Ablative Heat Shield Materials}

Michael Winter, University of Kentucky, KY

Margaret Stackpoole, NASA Ames Research Center, Moffett Field, CA

Anuscheh Nawaz, Sierra Lobo, Inc., NASA Ames Research Center, Moffett Field, CA Gregory Lewis Gonzales, ERC, Inc., NASA Ames Research Center, Moffett Field, CA Thanh Ho, Universities Space Research Association (USRA), NASA Ames Research Center, Moffett Field, CA

6th Ablation Workshop

April 10-11 2014, University of Illinois at Urbana-Champaign

\section{Outline:}

- Motivation and Introduction

- The mARC facility

- Sample Geometry and Seeding Procedure

- Optical Set-up and Results

- Conclusions and future plans 


\section{Introduction and Motivation}

- Current technologies for Thermal

Protection Systems (TPS) often involve ablative materials.

- One successful example is Phenolic Impregnated Carbon Ablator (PICA, e.g. on Stardust or MSL).

- Surface recession of the ablator is one of the main performance parameters influencing

- heat load to the inside

- shape changes (aerothermodynamics)

- structural integrity

- Currently, recession measurements usually are done after testing or flight $\rightarrow$ integrated recession over test/entry time

- To validate modeling, time resolved in

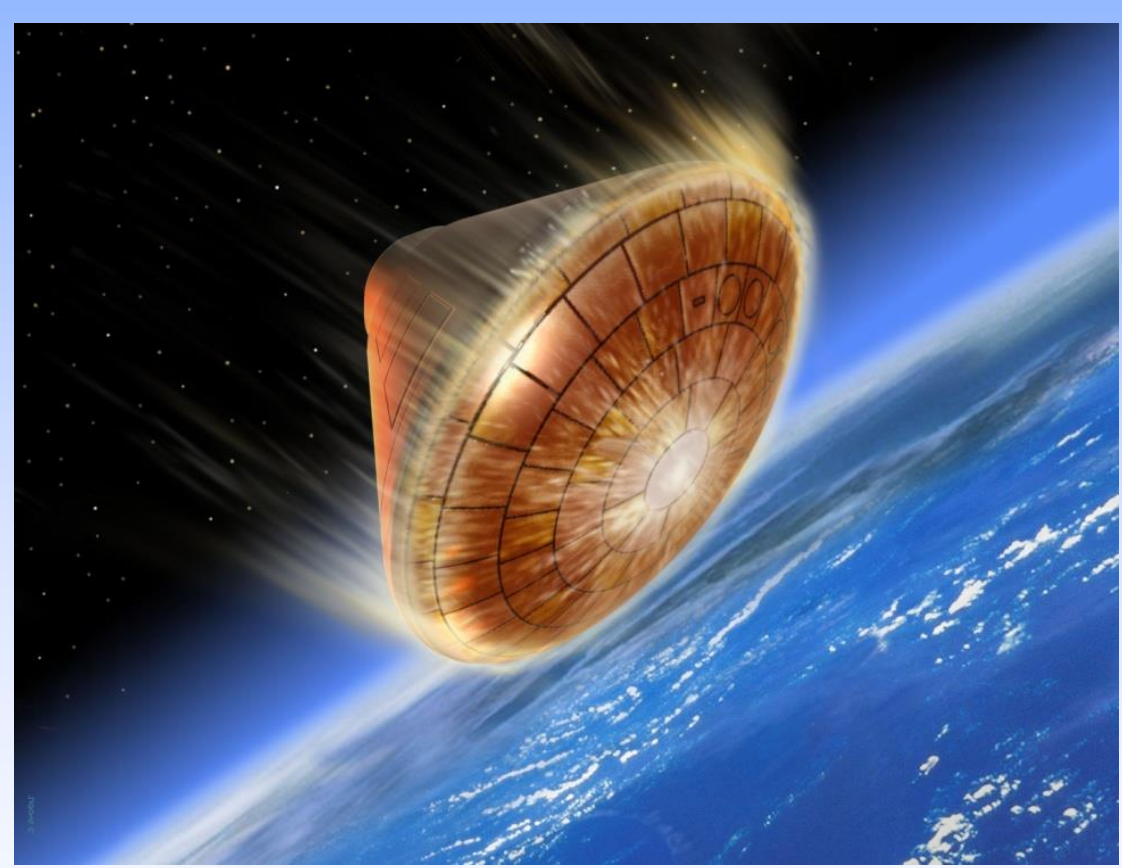

Source: http://www.dahl.com/wp-content/uploads/2013/04/ARD189.jpg situ measurements would be beneficial. 


\section{Introduction and Motivation}

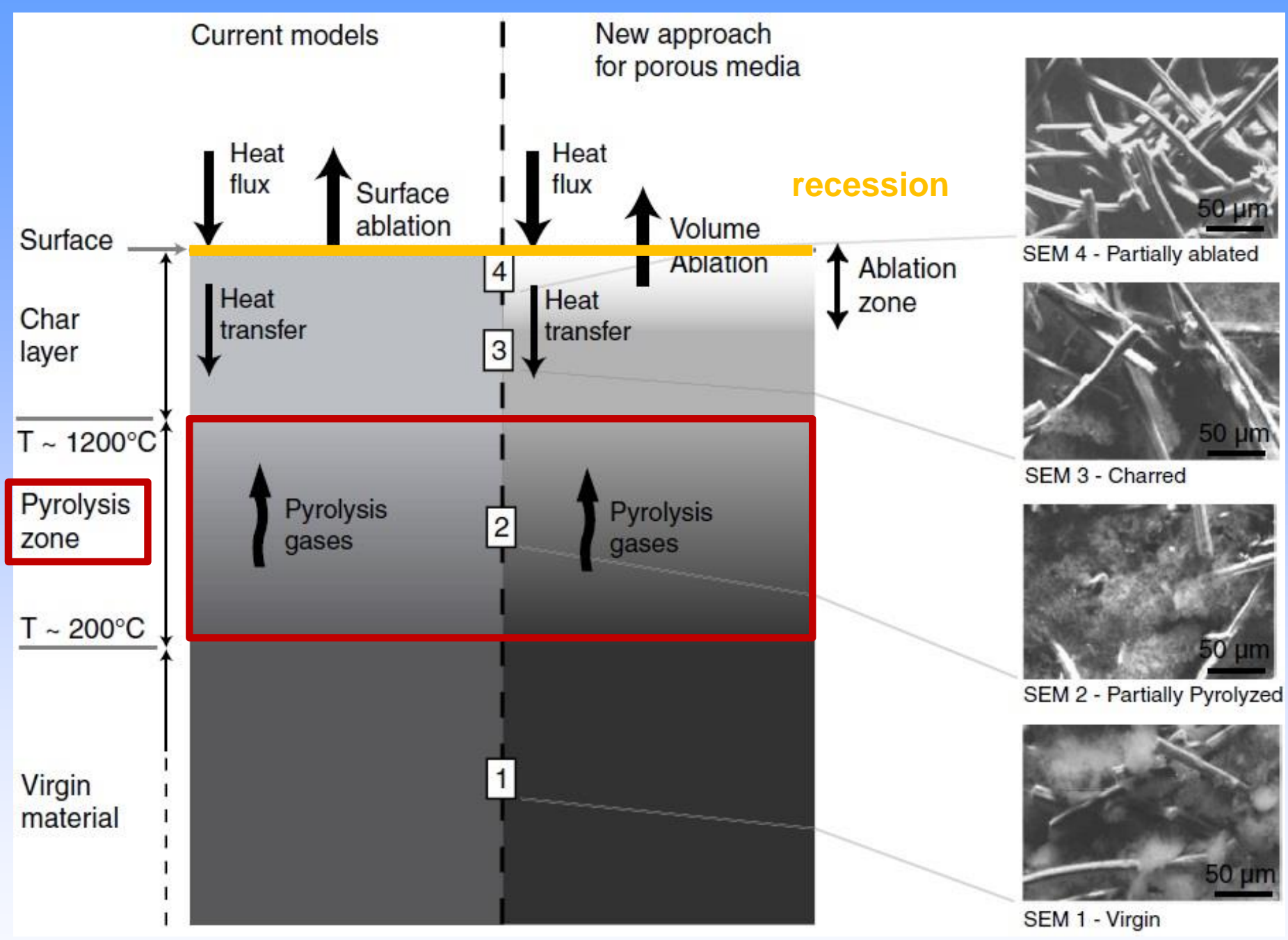

Ablative material response to a reentry heat flux: simplified sketches of two possible models and postflight SEM micrographs of the Stardust TPS 


\section{Flight data during Stardust Reentry Observation}

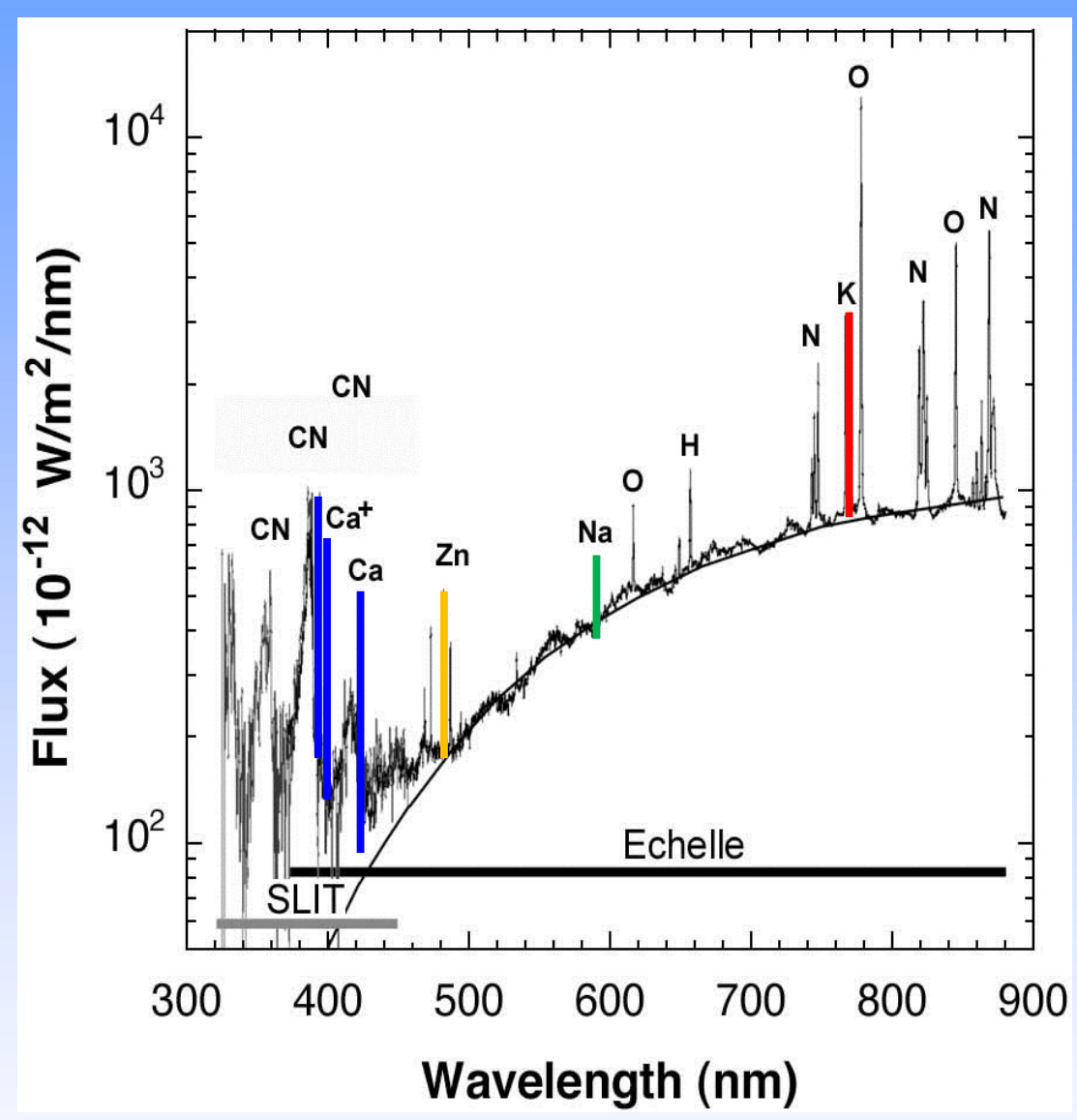

- Major emission sources:

- Strong continuum emission from hot surface

- Post-shock plasma (O, N,N2+)

- Ablating PICA (CN, C)

- In the observation data, additional emission was seen from:

- Ca, Ca+ (recently found to be part of the carbon fiber form)

- Zn from the white paint layer

- Na, K, assigned to impurities in the phenolic resin from the curing process and also seen during ground testing

- These signatures due to impurities stood out clearly against the plasma and surface emission $\rightarrow$ diffusion of boundary layer species into the post shock region

$\rightarrow$ strong emission.

$\rightarrow$ Idea for recession measurements:

- Bury tracer elements at a defined depth inside the TPS

$\rightarrow$ once the recession reaches this depth, the tracer elements diffuse into the post-shock layer, start emitting at defined wavelengths and can be detected with emission spectroscopy. 


\section{Optical Recession/char-depth Sensor

Tracer element (Coating/paint)

shock/post-shock system

Multiple materials $\rightarrow$

- Multiple locations

$\rightarrow$ spatial information w/o optical spatial res.

- Multiple depths $\rightarrow$ Time trace

Possible candidates

- Al (paint/powder/coating)

- Cu (not for arc jet testing)

- $\mathrm{Cs}, \mathrm{Li}, \mathrm{Mg}$... (everything with strong emission lines)

- Low melting point or part of phenolic $\rightarrow$ char depth sensor (e.g. Al)

- Higher melting point or sublimation

$\rightarrow$ recession sensor (e.g. Mg)

blowing layer material sample

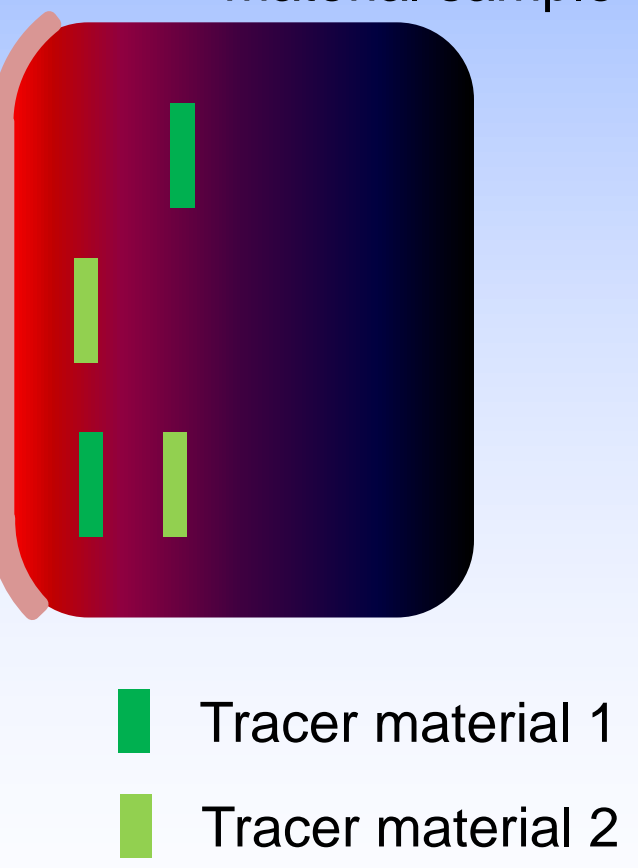




\section{Optical Recession/Char-depth Sensor

Tracer element (Coating/paint) Mounted from the back $\rightarrow$ backside TC possible

Tracer plug (e.g. PICA) Mounted from the front $\rightarrow$ no impact to TPS integrity
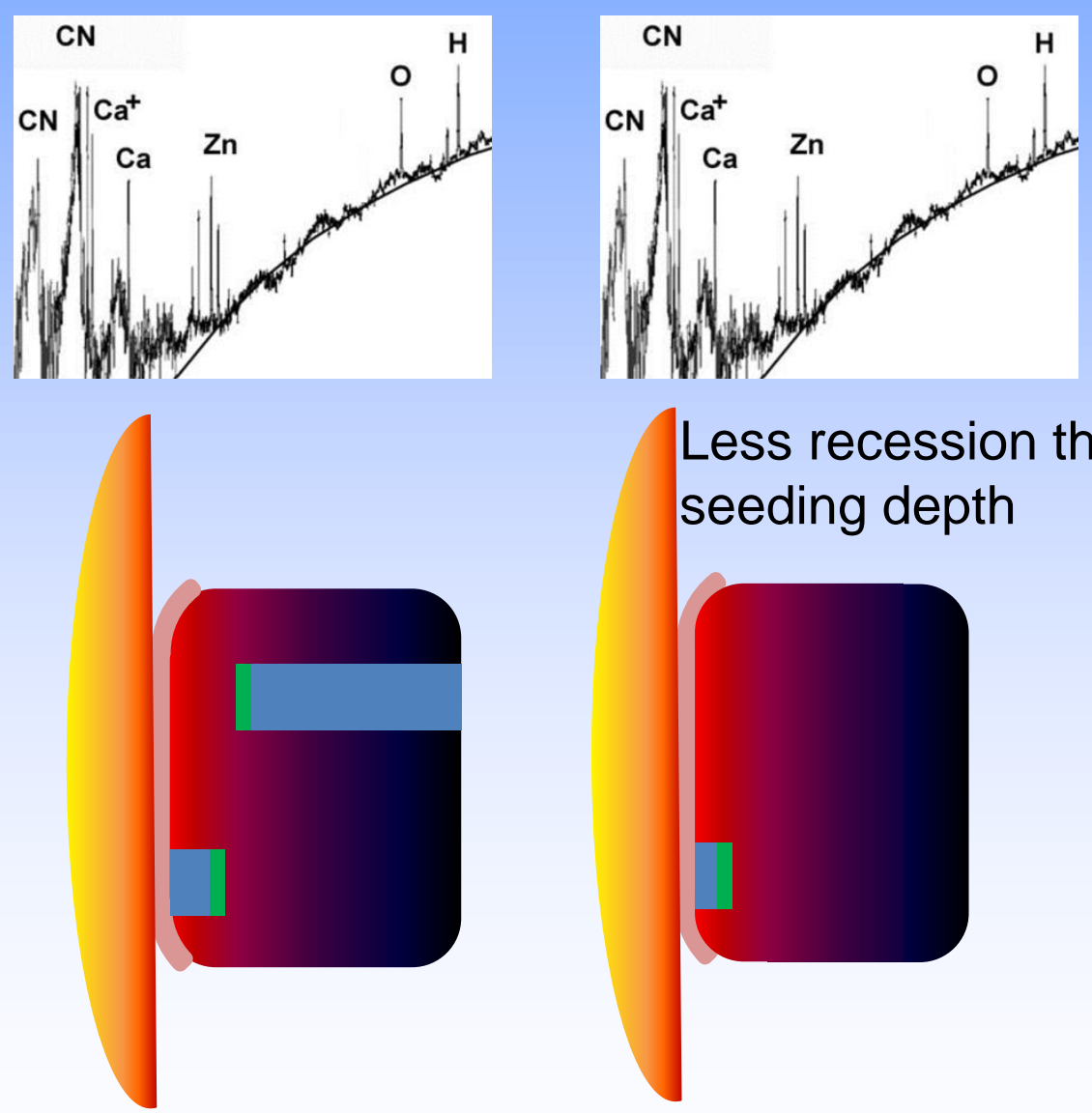

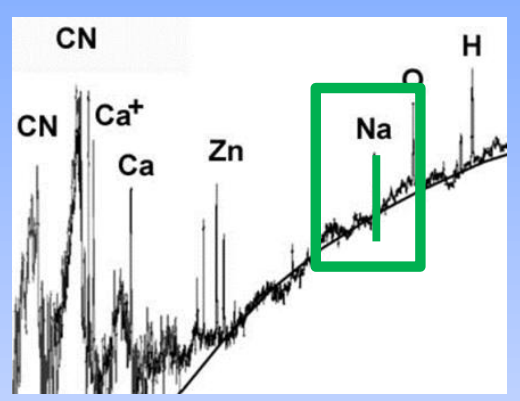

Less recession than seeding depth

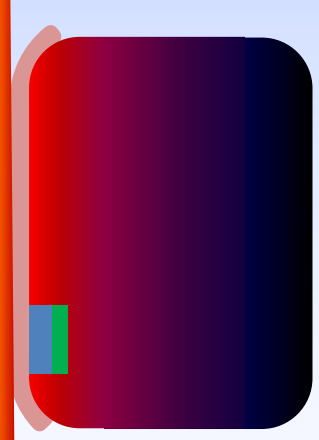

Recession reaches seeding depth

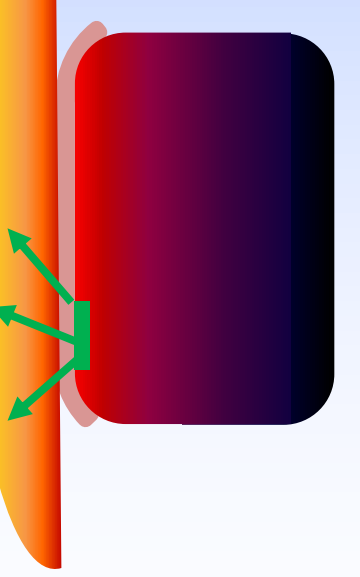

Goals of this work - demonstration of feasibility of the principle through testing in the NASA Ames mArc facility.

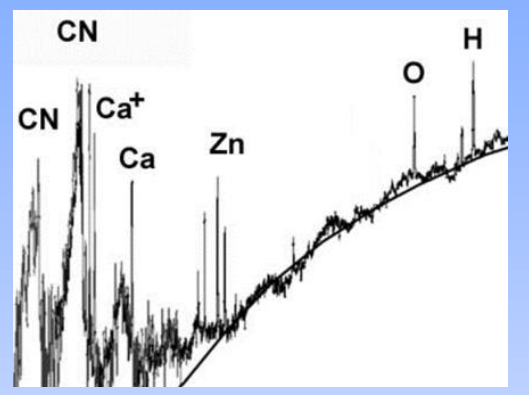

Recession exceeds seeding depth

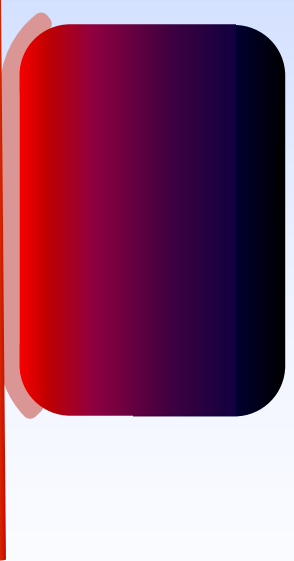


- subscale segmented arc heater, $30 \mathrm{~kW}$, up to $200 \mathrm{~A} \mathrm{DC}$

- for this campaign operated at $70 \mathrm{~A}$

- flow rate $0.45 \mathrm{~g} / \mathrm{s}$ of air

- cooled thoriated tungsten tipped cathode, water-cooled copper anode

- $1.3 \mathrm{~cm}$ diameter constricted arc column channel followed by a converging-diverging nozzle (1 $\mathrm{cm}$ exit diameter)

$\rightarrow$ plasma column approximately $1.3 \mathrm{~cm}$ in diameter

- cylindrical vacuum chamber of approximately $0.61 \mathrm{~m}$ in length and $0.3 \mathrm{~m}$ diameter

- chamber background pressures consistently approximately $2.67 \mathrm{kPa}$ (20 Torr)
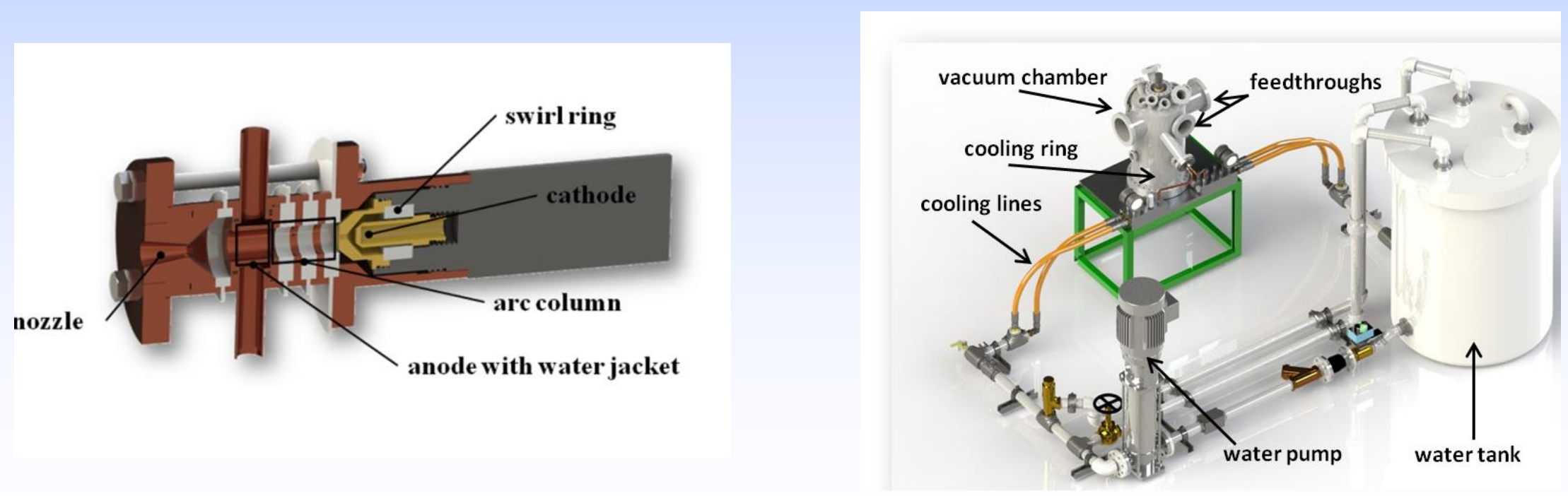

Winter, M.W., Stackpoole, M., Nawaz, A., Gonzales, G. L., and Ho, T.: "Remote Recession Sensing of Ablative Heat 


\section{Plasma Conditions - Calibration Runs}

- Calibration runs were performed to obtain stagnation heat flux at the test location at $5 \mathrm{~mm}$ distance to the nozzle by using a $4.76 \mathrm{~mm}(0.187 \mathrm{inch})$ diameter hemispherical watercooled Gardon Gage

- Due to the high heat fluxes, the Gardon Gage exposure time was chosen to $\sim 0.15 \mathrm{~s}$ while data was continuously acquired.

Dimensions and mounting of Gardon Gage.

$0.187^{\prime \prime}$

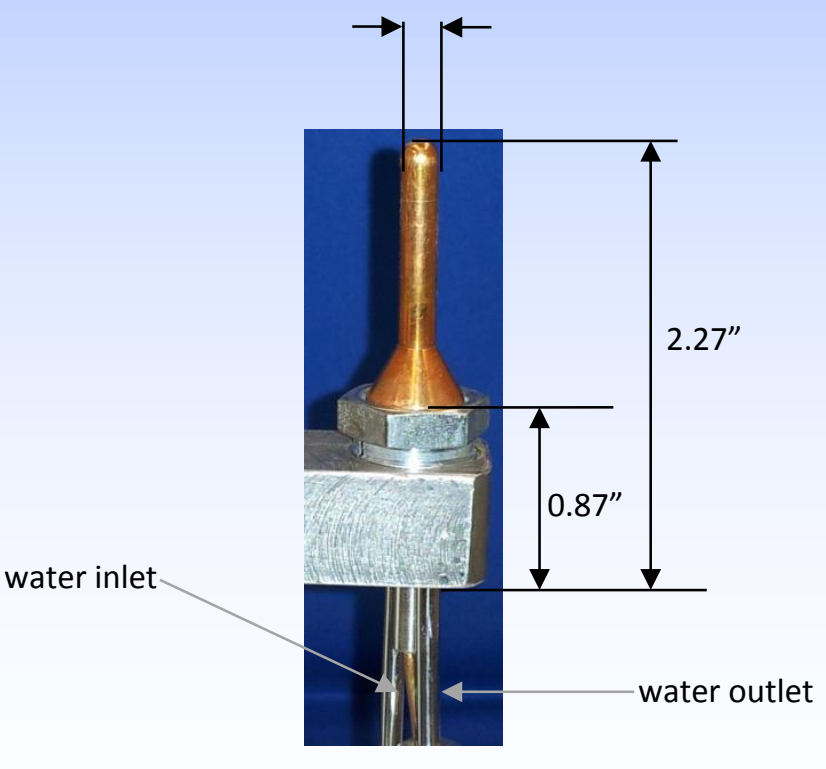

Sample calorimeter output for heat flux evaluation.

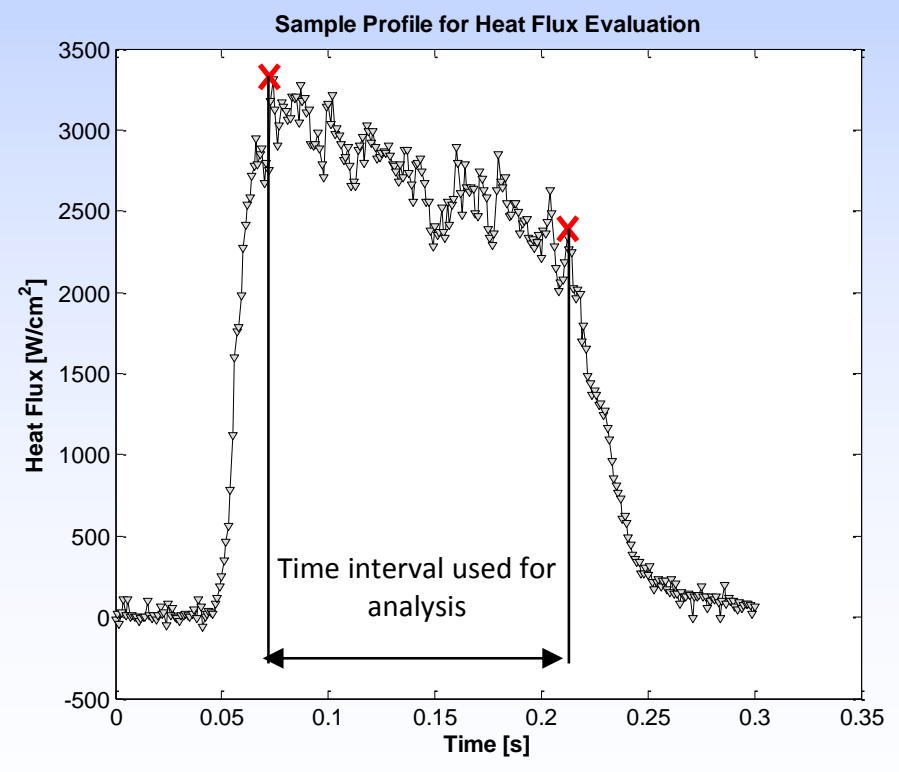




\section{Plasma Conditions - Calibration Runs}

- Calibration runs were performed to obtain stagnation heat flux at the test location at $5 \mathrm{~mm}$ distance to the nozzle by using a $4.76 \mathrm{~mm}(0.187 \mathrm{inch})$ diameter hemispherical watercooled Gardon Gage

- Due to the high heat fluxes, the Gardon Gage exposure time was chosen to $\sim 0.15 \mathrm{~s}$ while data was continuously acquired.

- Repeatability of the measured heat fluxes between different runs was quite good.

- Uncertainty of the measured heat fluxes estimated to $\pm 10 \%$ $\rightarrow$ average value of the calibration runs of $2575 \mathrm{~W} / \mathrm{cm}^{2}$ used.

Sample calorimeter output for heat flux evaluation.

\begin{tabular}{|c|c|}
\hline Test \# & $\begin{array}{c}\text { Heat Flux } \\
{\left[\mathrm{W} / \mathrm{cm}^{2}\right]}\end{array}$ \\
\hline 1 & 2500 \\
\hline 2 & 2600 \\
\hline 3 & 2600 \\
\hline 4 & 2600 \\
\hline
\end{tabular}

Summary of stagnation heat flux for calibration runs.

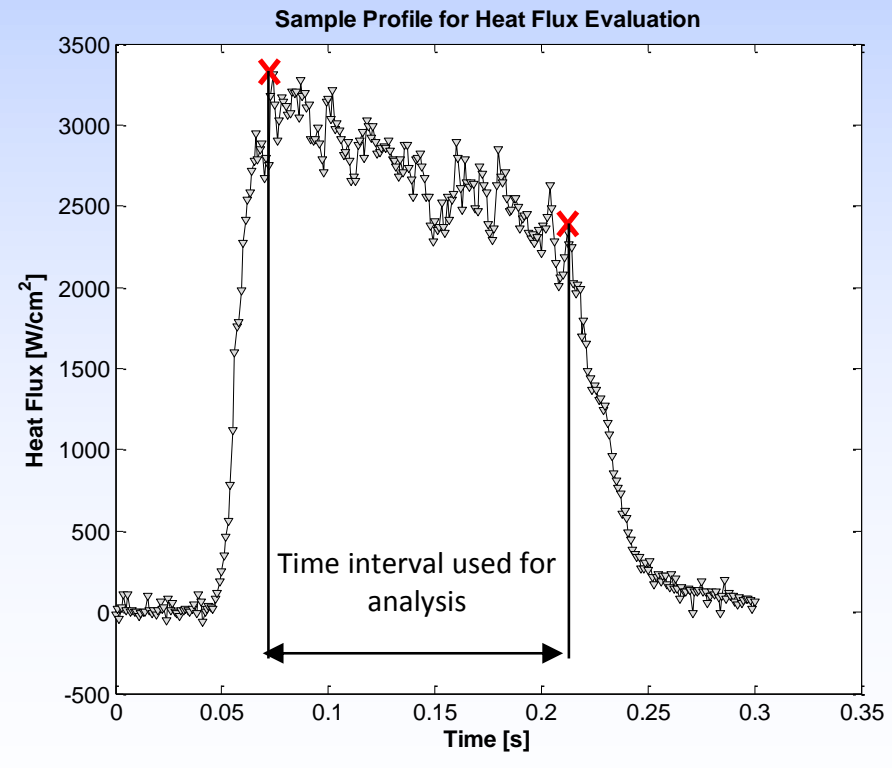




\section{Plasma Conditions - Calibration Runs}

- Calibration runs were performed to obtain stagnation heat flux at the test location at $5 \mathrm{~mm}$ distance to the nozzle by using a $4.76 \mathrm{~mm}(0.187 \mathrm{inch})$ diameter hemispherical watercooled Gardon Gage

- Due to the high heat fluxes, the Gardon Gage exposure time was chosen to $\sim 0.15 \mathrm{~s}$ while data was continuously acquired.

- Repeatability of the measured heat fluxes between different runs was quite good.

- Uncertainty of the measured heat fluxes estimated to $\pm 10 \%$ $\rightarrow$ average value of the calibration runs of $2575 \mathrm{~W} / \mathrm{cm}^{2}$ used.

- This value is the heat flux to a hemispherical surface with a radius of $2.38 \mathrm{~cm}$.

- The heat flux to the flat face material sample $(8.38 \mathrm{~cm}$ square) follows from the relations given by Zoby and Sullivan:

\begin{tabular}{|c|c|}
\hline Test \# & $\begin{array}{c}\text { Heat Flux } \\
{\left[\mathrm{W} / \mathrm{cm}^{2}\right]}\end{array}$ \\
\hline 1 & 2500 \\
\hline 2 & 2600 \\
\hline 3 & 2600 \\
\hline 4 & 2600 \\
\hline
\end{tabular}

$$
\dot{q}_{B B}=\dot{q}_{H e m i} \sqrt{\frac{r_{\text {Hemi }}}{r_{B B}}}=2575 \sqrt{\frac{2.38}{14.7}} \frac{\mathrm{W}}{\mathrm{cm}^{2}}=1036 \frac{\mathrm{W}}{\mathrm{cm}^{2}}
$$

Summary of stagnation heat flux for calibration runs. 
- From the total recession of the sample and the test time of $10 \mathrm{~s}$, an average total recession rate was calculated. The total recession varied over the surface, though.

- At the center of the sample the recession was mostly constant with highest recession values of about $0.056 \mathrm{~cm} / \mathrm{s}$ for the test with emission spectroscopy measurements.

- Seeding materials considered were metals, oxides and salts of $\mathrm{Al}, \mathrm{Ti}, \mathrm{Mg}$ and $\mathrm{Si}$. Due to limited test time not all materials were evaluated in the mARC facility. The results presented focus on samples seeded with $\mathrm{NaCl}$ and $\mathrm{MgCl}$.

- The PICA coupons were drilled at given locations and the seeding rods (extruded with a polymer matrix) were inserted into the PICA and sealed using a PICA like paste allowing the seeding material to be encapsulated within the

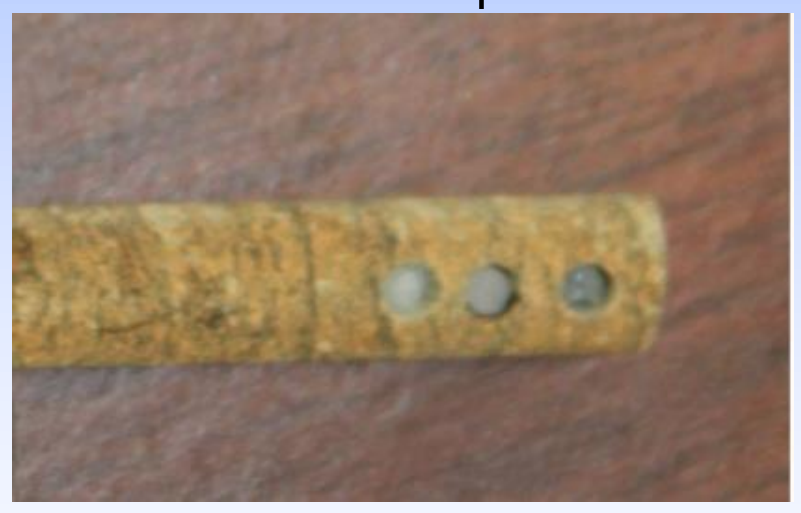

PICA cylindrical test coupons (6.35mm diameter) with seeded materials inserted in the PICA prior

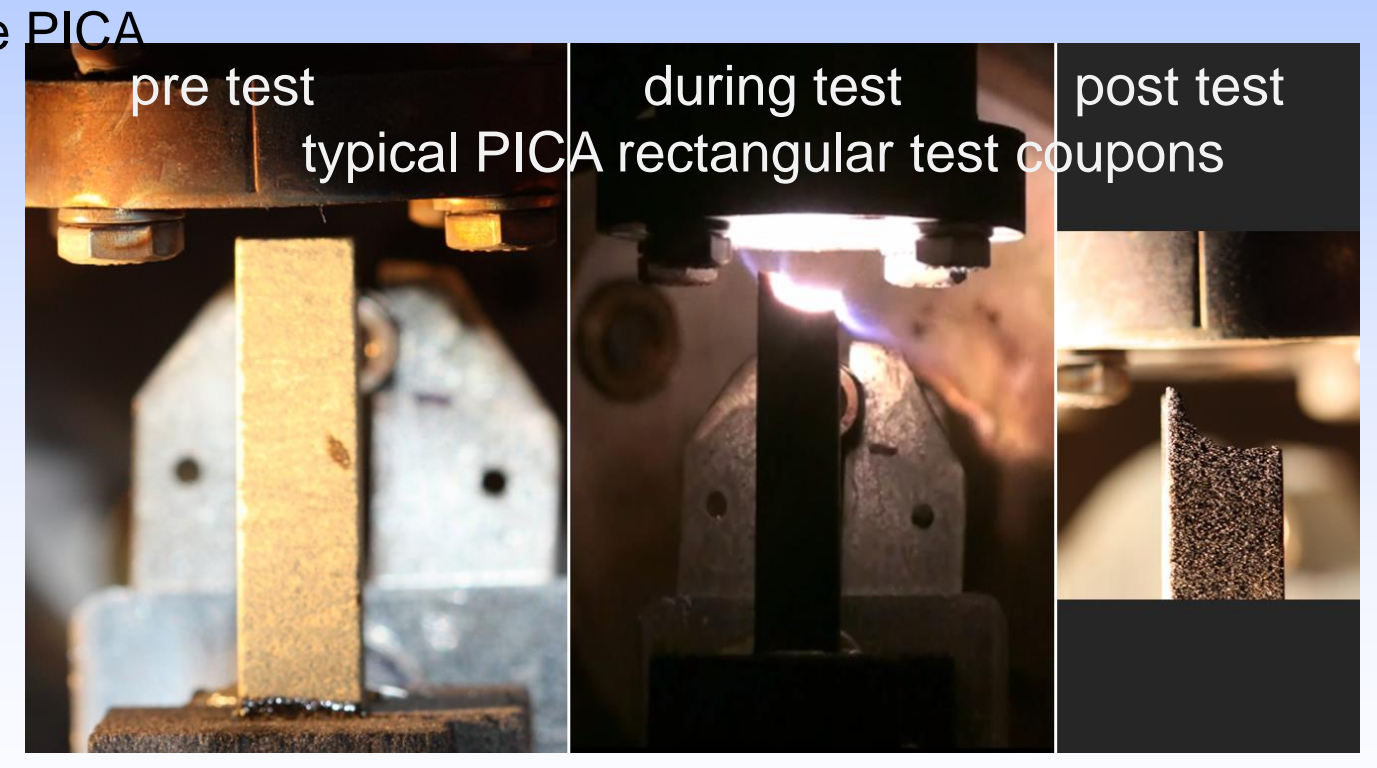
to encapsulating 


\section{Optical set-up}

- Focal point imaging system with a $50 \mathrm{~mm}$ spherical mirror, focal length $305 \mathrm{~mm}$ $\rightarrow$ mostly collimated beam with the mirror diameter.

- The light was focused on a $200 \mathrm{~mm}$ optical fiber and detected with an miniaturized spectrometer (Avantes AvaSpec-3648-USB2-UA, nominal wavelength range 180-1100nm).

- The $f$-number of the fiber (numerical aperture $n_{A}=0.22$ ) was matched using an aperture between mirror and fiber.

- The beam cross section covered the arc-jet nozzle exit with its upper edge, the virgin sample surface placed approximately at $10 \mathrm{~mm}$ from the upper edge of the detection beam.

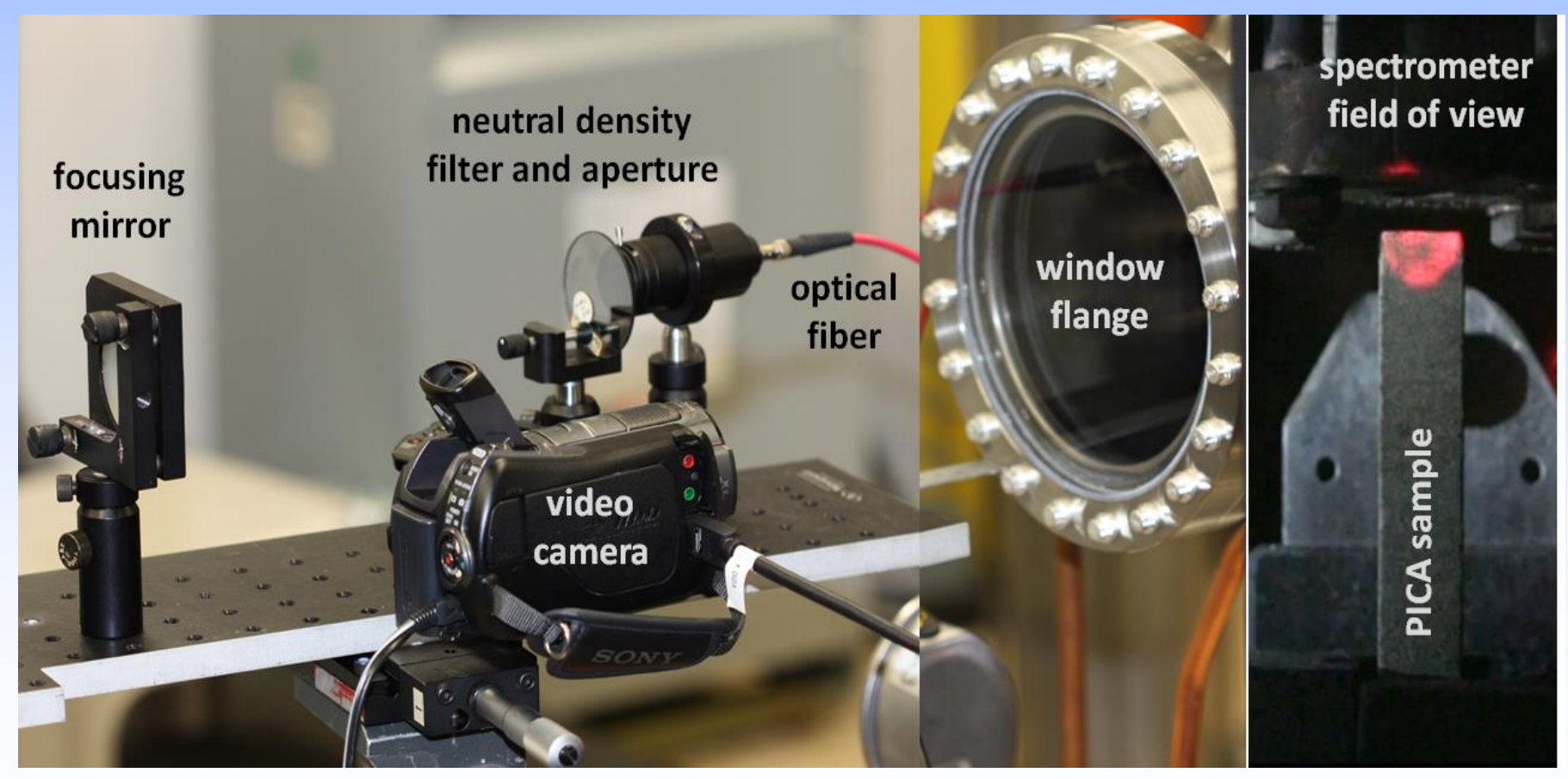

Winter, M.W., Stackpoole, M., Nawaz, A., Gonzales, G. L., and Ho, T.: "Remote Recession Sensing of Ablative Heat 


\section{Results: spectra with test time}

- During recession, the surface did move through the beam center towards the lower edge. $\rightarrow$ at different times, different parts of the sample surface were visible for the spectrometer

- With test time, increasing continuum radiation detected.

$\rightarrow$ Absolute intensity not considered appropriately calibrated and is not the primary information ...

- The measured spectra show continuous emission from the glowing sample, CN emission from ablation products interacting with the post-shock plasma and emission lines due to the seeding material $(\mathrm{NaCl}$ and $\mathrm{MgCl})$.

- Emission lines of $\mathrm{Mg}(280 \mathrm{~nm}, 285 \mathrm{~nm}$, and $518 \mathrm{~nm})$ and $\mathrm{Na}(568 \mathrm{~nm}, 589 \mathrm{~nm}$, and $819 \mathrm{~nm})$ were identified in the arc-jet plasmaby a comparison with synthetic spectra at $9000 \mathrm{~K}$ (arbitrarily chosen) based on NIST data using Boltzmann distributions.

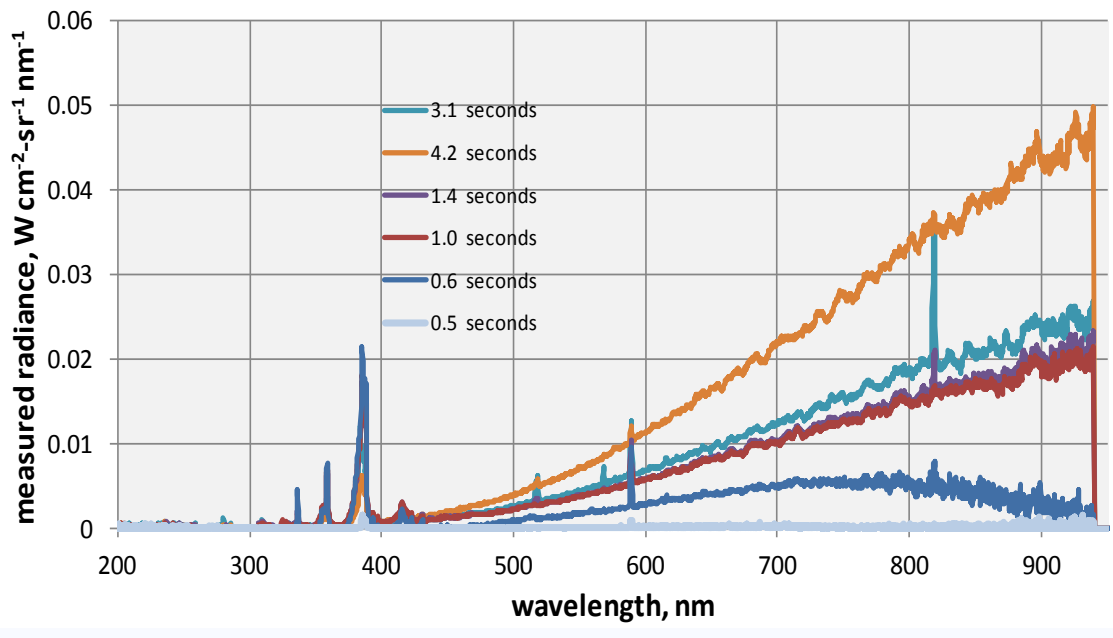

Selected emission spectra for increasing test time

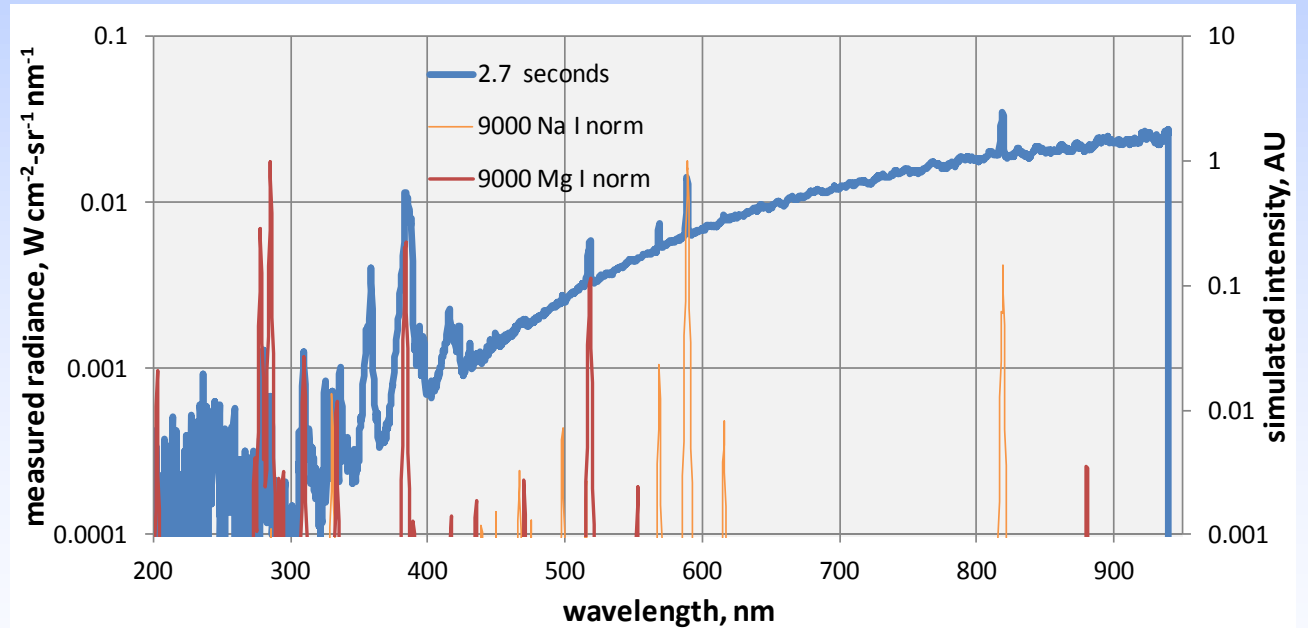

Measured spectra in comparison to NIST data. 
- All identified lines started showing up about 1 second after sample insertion and disappeared at roughly 4 seconds.

- The Na line at $589 \mathrm{~nm}$ was present right after sample insertion but disappeared together with the other emission lines (residual $\mathrm{Na}$ from the ambient air or on the sample surface?).

- Diameter of the seeding rod $(1.5 \mathrm{~mm})$ is chosen as thickness of the seeding layer

- Time for Mg emission $(518 \mathrm{~nm})>20 \%$ of $\max : \Delta \mathrm{t}=2.4 \mathrm{~s} \rightarrow$ recession rate $0.66 \mathrm{~mm} / \mathrm{s}$ First and last appearance of $\mathrm{Mg}$ emission: $\Delta \mathrm{t}=3.5 \mathrm{~s} \rightarrow$ recession rate $0.44 \mathrm{~mm} / \mathrm{s}$ I recession rate from total recession in the center region of the sample $\overline{0.5}$ to $0.6 \overline{\mathrm{mm}} \overline{\mathrm{s}}$

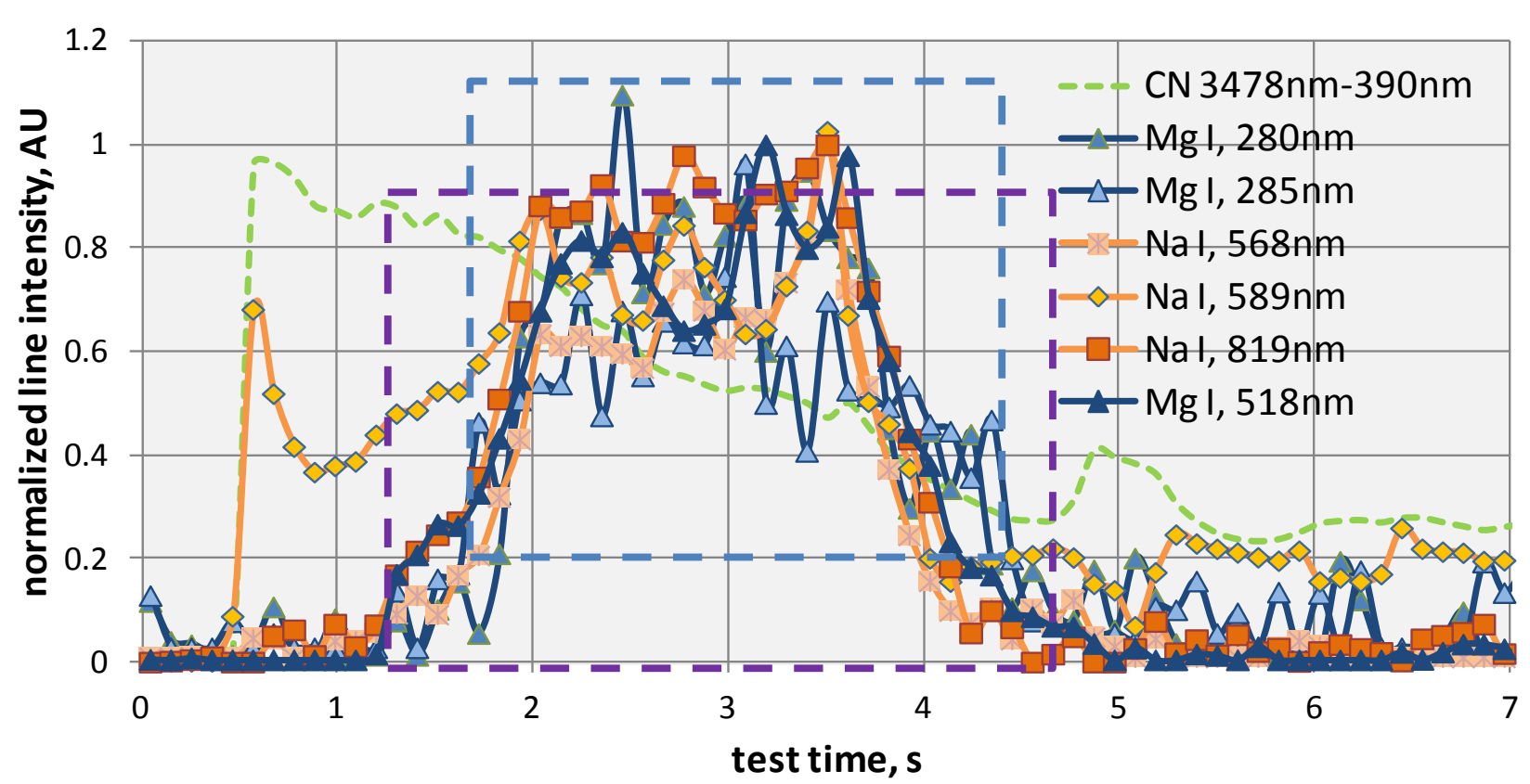

Time trace of spectrally integrated line emission of sodium and magnesium 


\section{Results}

- Taking into account the limited performance of the mARC facility (beam profile, beam diameter, Mach number)

$\rightarrow$ reasonable agreement with data from testing in the large arc-jet facilities.

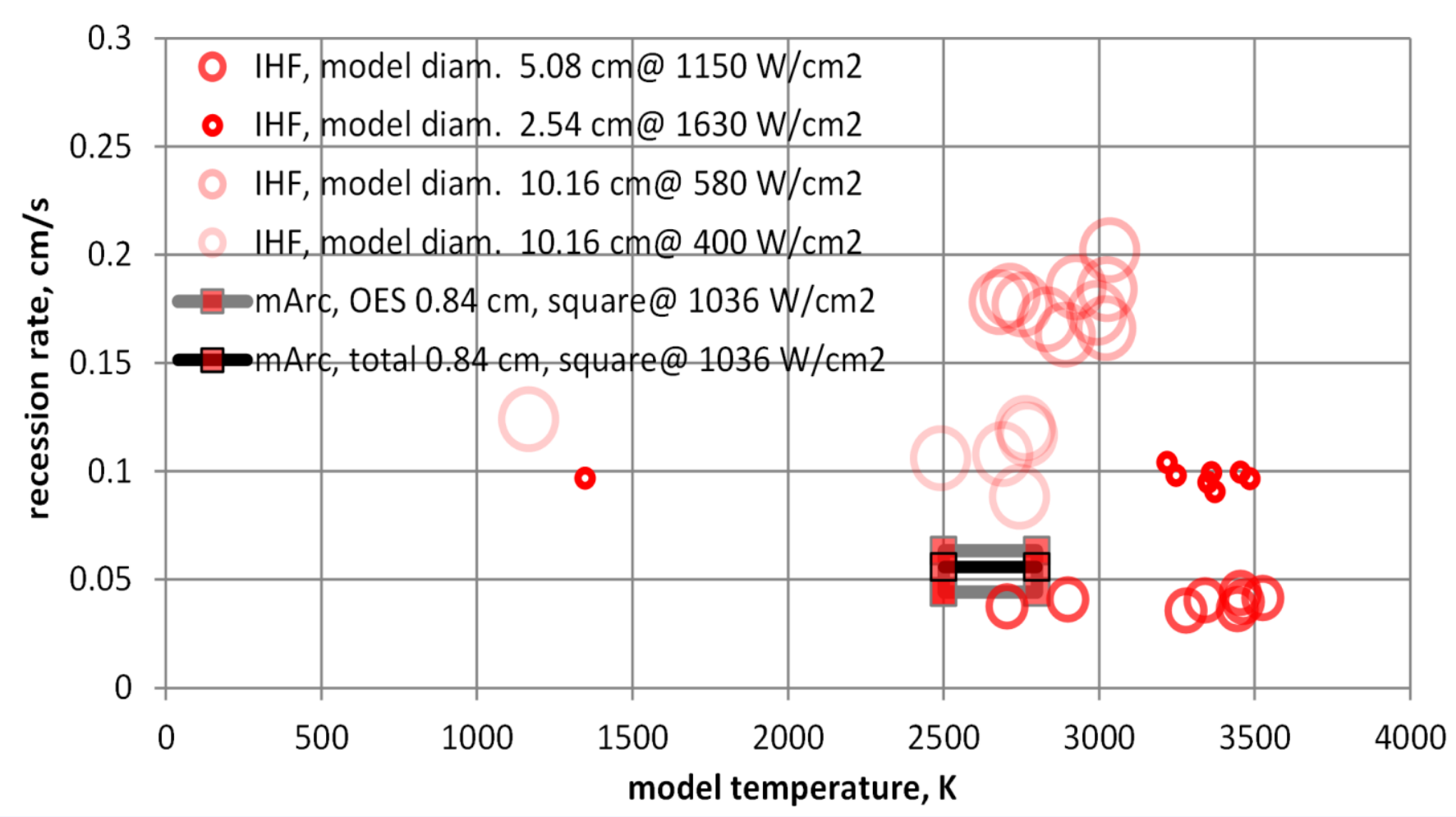

Recession rates of PICA during mArc testing compared to data obtained in the NASA Ames IHF arc-jet facility vs. sample temperature 
- The feasibility tests for this method are considered successful although testing under more controlled conditions is recommended for a further characterization.

- The recession rates determined from the emission spectroscopy measurements agree well with recession rates determined from absolute recession measurements of the material samples during this test campaign.

- An application for ground testing but more important for in-flight applications during real re-entry flight seems promising.

- Since spatial resolution is obtained through the location of the seeding material in the heat shield, the optical system does not need to happen spatially resolved (either through on-board or external observation).

- An extension of the sensor to a char depth sensor seems possible through a choice of seeding materials with lower melting/evaporation point, which then would be evaporated with the pyrolysis gases once the pyrolysis zone reaches the seeding depth. 
Thanks for your attention !

Open for

\section{Questions?}




\section{Backup Slides}




\section{Results: spectra with test time}

- During recession, the surface did move through the beam center towards the lower edge. $\rightarrow$ at different times, different parts of the sample surface were visible for the spectrometer

- Spectrometer sensitivity across the field of view showed slight variations during pre-tests assigned to inhomogeneities of mirror and fiber

$\rightarrow$ the same emission at different locations in the field of view might yield a different instrument response.

\section{spectrometer} field of view

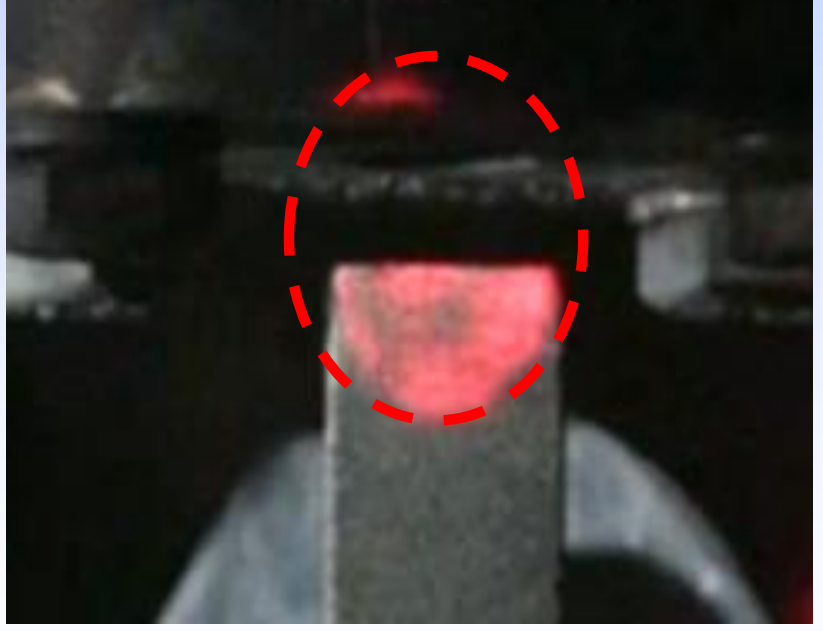




\section{Results}

- To get an estimate of the sample temperature, Planck radiation was calculated.

- By fitting the spectral shape (with $\varepsilon=0.9$ ), an average temperature was obtained.

- At the beginning of the test (3s after insertion), 2500K Planck radiation fits the measured spectra best, at the end (10s after insertion), this value increases to about $2750 \mathrm{~K}$.

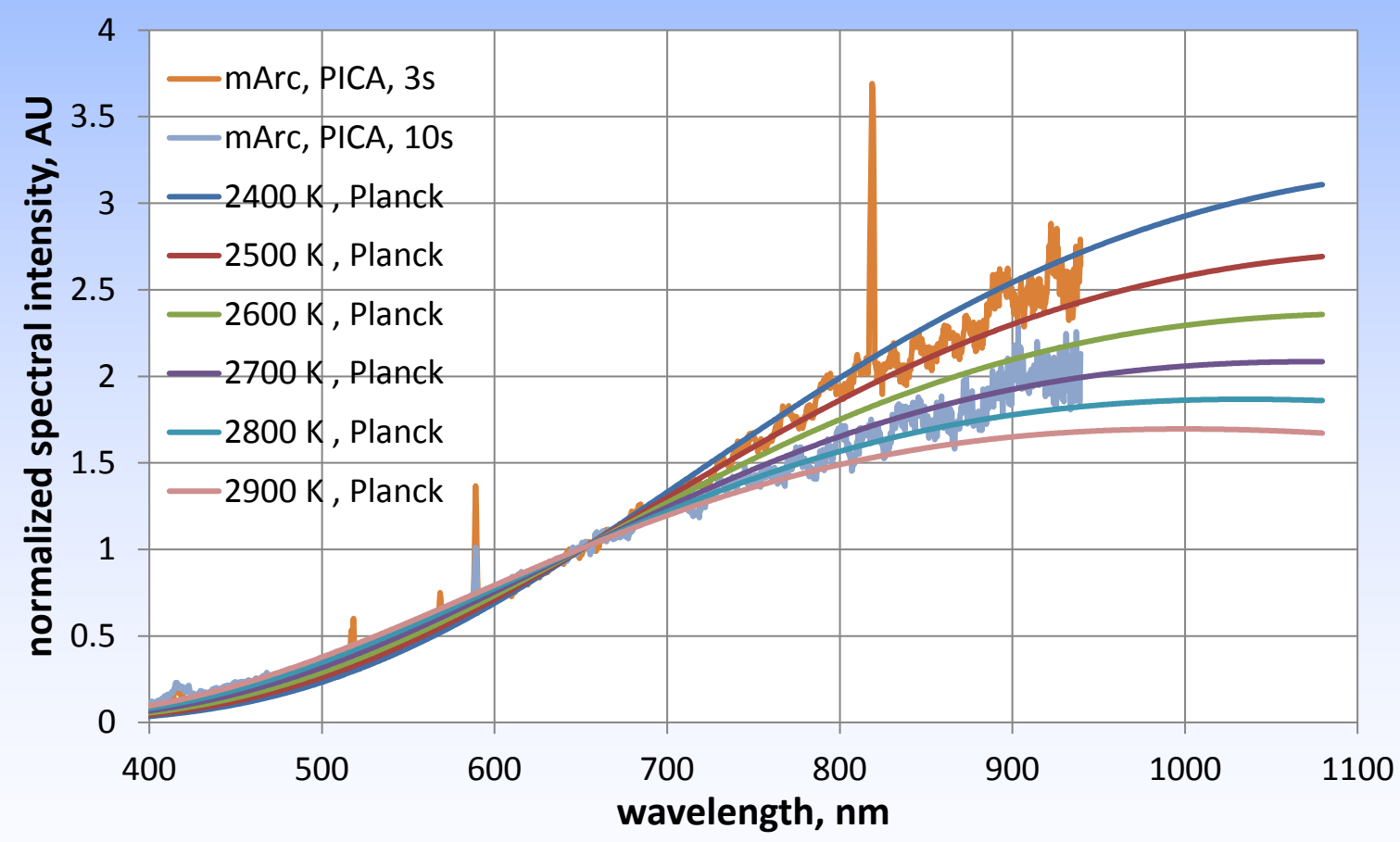

Measured spectra at 3 and 10 seconds after sample insertion in comparison to Planck radiation at temperatures between $2400 \mathrm{~K}$ and $2900 \mathrm{~K}$ on linear scale. 21 All spectra are normalized to the emission between $600 \mathrm{~nm}$ and $700 \mathrm{~nm}$ 


\section{Results}

- To get an estimate of the surface temperature, Planck radiation was calculated.

- By fitting the spectral shape (with $\varepsilon=0.9$ ), an average temperature was obtained.

- At the beginning of the test (3s after insertion), 2500K Planck radiation fits the measured spectra best, at the end (10s after insertion), this value increases to about $2750 \mathrm{~K}$.

- Since the spectrometer view angle provides only an obstructed view on the front surface (getting better with the surface recessing), this temperature is considered a lower bound for the actual front surface temperature

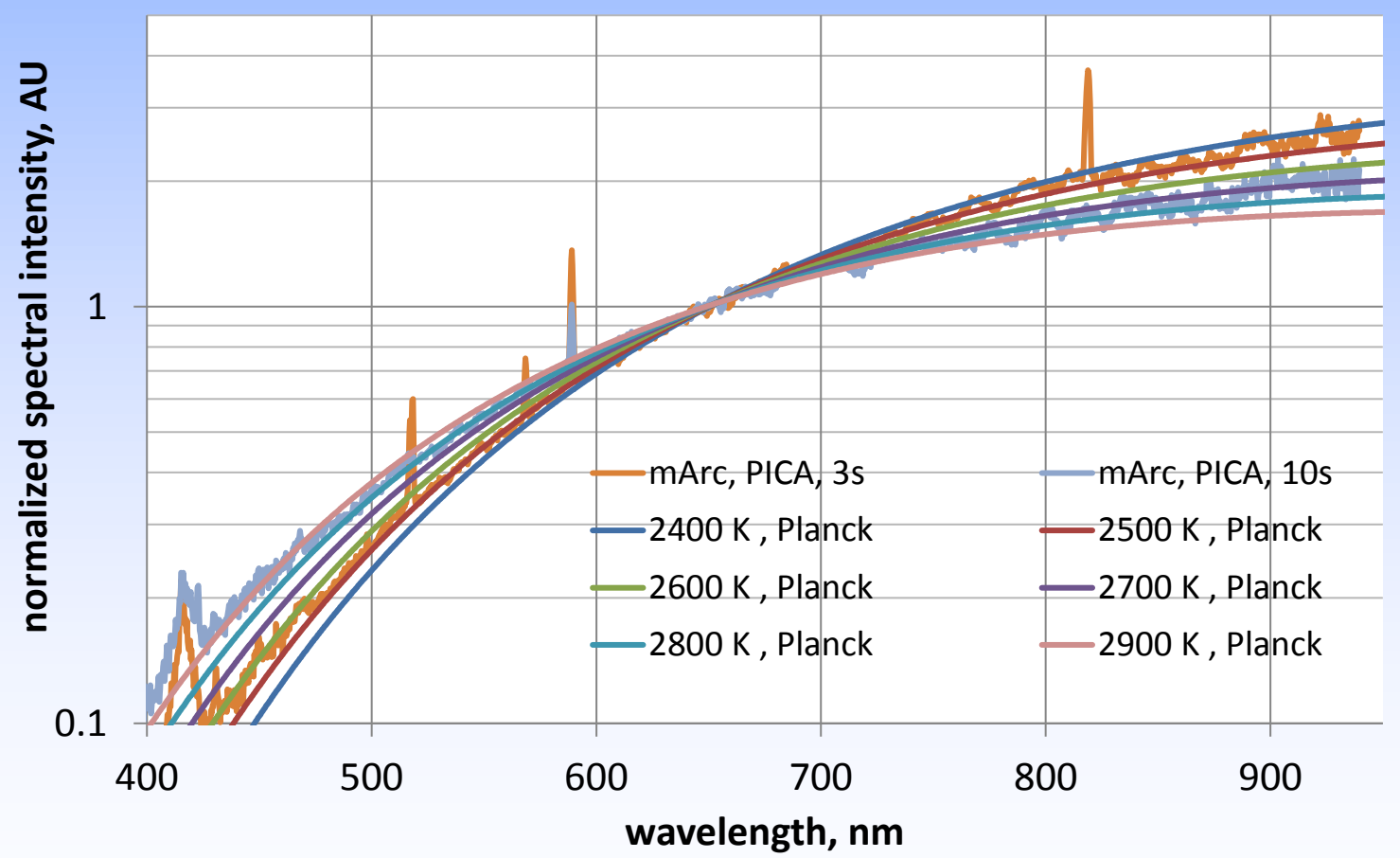

Measured spectra at 3 and 10 seconds after sample insertion in comparison to Planck radiation at temperatures between $2400 \mathrm{~K}$ and $2900 \mathrm{~K}$ on log scale. All spectra are normalized to the emission between $600 \mathrm{~nm}$ and $700 \mathrm{~nm}$ 


\section{Optical Emission Spectroscopy (OES): Set-up during SPRITE testing}

- Emission spectroscopy measurements conducted to identify radiating species

- Two fiber coupled spectrometers used (200nm - 950nm) with focusing mirror

- Before test, optical paths close to each other barely touching the SPRITE nose tip

- Alignment before evacuation through a laser fed to the fibers

- Material recession would change the measurement position relative to the surface

- Continuous data acquisition during SPRITE and calorimeter insertion

repetition rate $\sim 2 \mathrm{~Hz} \rightarrow 81$ spectra for the PICA model, 4 spectra for the calorimeter

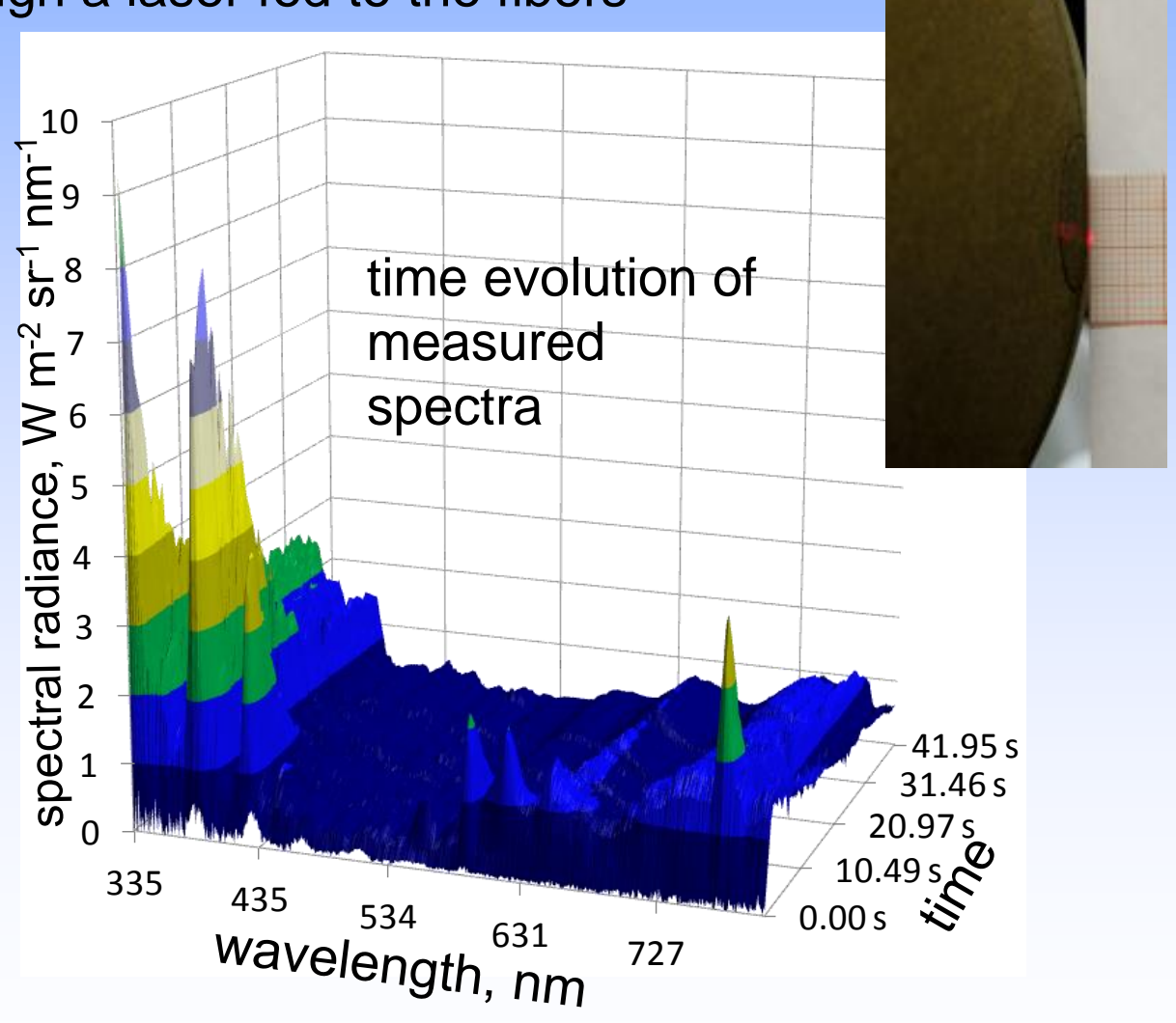




\section{OES: Acquired Data - Overview}

- At the end of the model insertion (50s), spectra are qualitatively similar to the ones in front of the copper calorimeter $\rightarrow$ no effect from ablation, outside BL

- Atom lines from $\mathrm{Cu}, \mathrm{O}, \mathrm{N}$, molecular emission from $\mathrm{N}_{2}$ and $\mathrm{N}_{2}{ }^{+}$

- Shortly after insertion, emission peaks

- Continuum emission seen

\section{$\rightarrow$ surface radiation}

- Additional atom emission from $\mathrm{Ca}, \mathrm{K}$ and $\mathrm{Na}$ (also seen during Stardust observation)

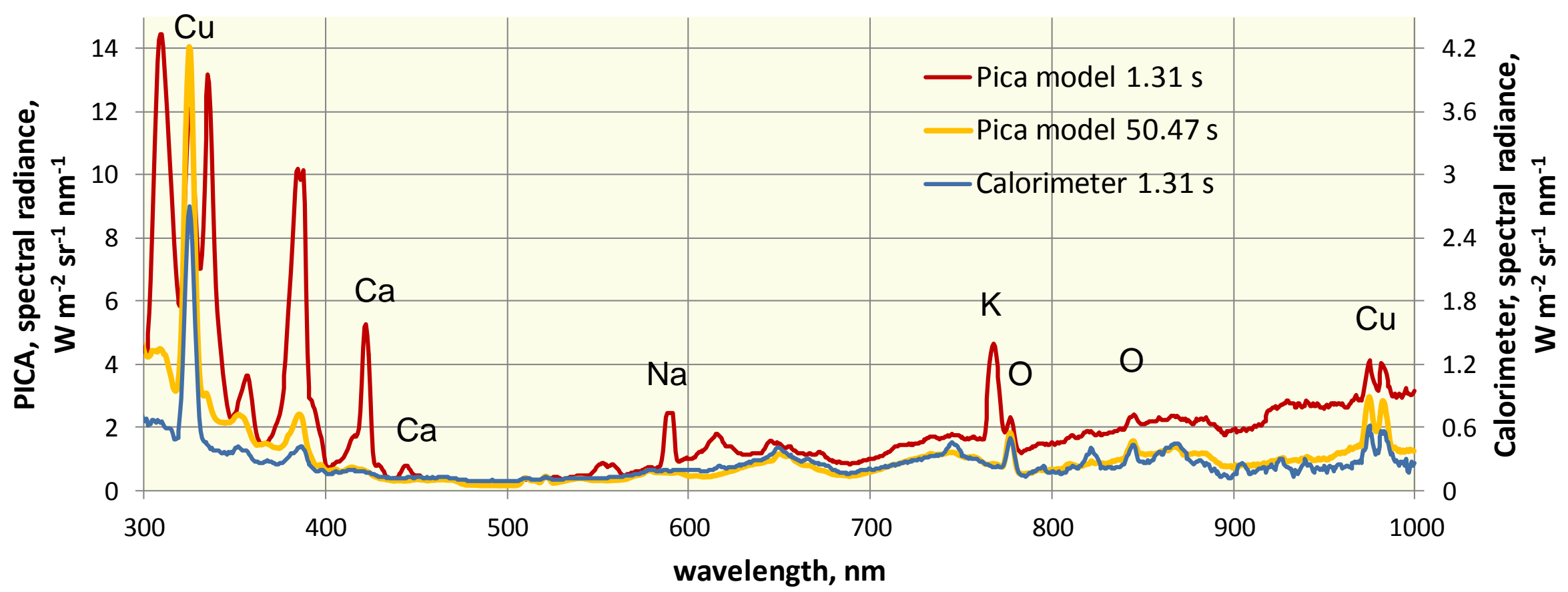

D. Empey, K. Skokova, P. Agrawal, G. Swanson, D. Prabhu, K. Peterson, M. Winter, E. Venkatapathy, Small Probe Reentry Investigation for TPS Engineering (SPRITE), AIAA-2012-0215, 50th AIAA Aerospace Sciences Meeting, Nashville, Tennessee, 9 - 12 Jan 2012. 


\section{OES: Acquired Data - UV-spectra}

- Difference between end and start of insertion should characterize the effect of ablation.

- Identified species: $\mathrm{NH}$ and $\mathrm{OH}, \mathrm{CN}$ (strongly overlapping with $\mathrm{N}_{2}{ }^{+}$)

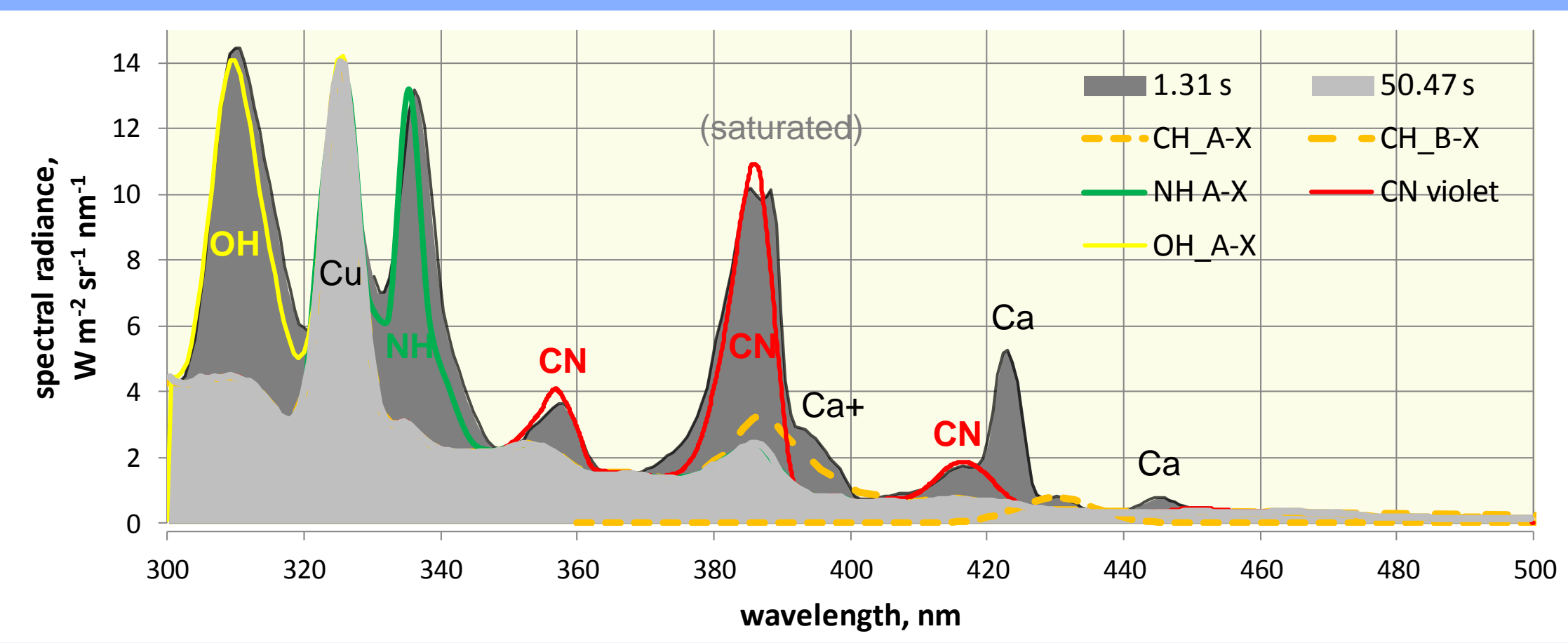

\section{Conclusions:}

- The ablation products $\mathrm{OH}, \mathrm{NH}$, and $\mathrm{CN}$ were seen in emission from the post shock/boundary layer

- Further characterization (e.g. for $\mathrm{CH}$ ) requires experiments in higher spectral resolution.

- The role of $\mathrm{K}$ and $\mathrm{Na}$ as strong atom emissions is still to be verified, $\mathrm{H}$ was not seen. 


\section{OES-SPRITE:}

UV-spectra

- Difference between end and start of insertion should characterize the effect of ablation.

- Identified species: $\mathrm{NH}$ and $\mathrm{OH}, \mathrm{CN}$ (strongly overlapping with $\mathrm{N}_{2}{ }^{+}$)

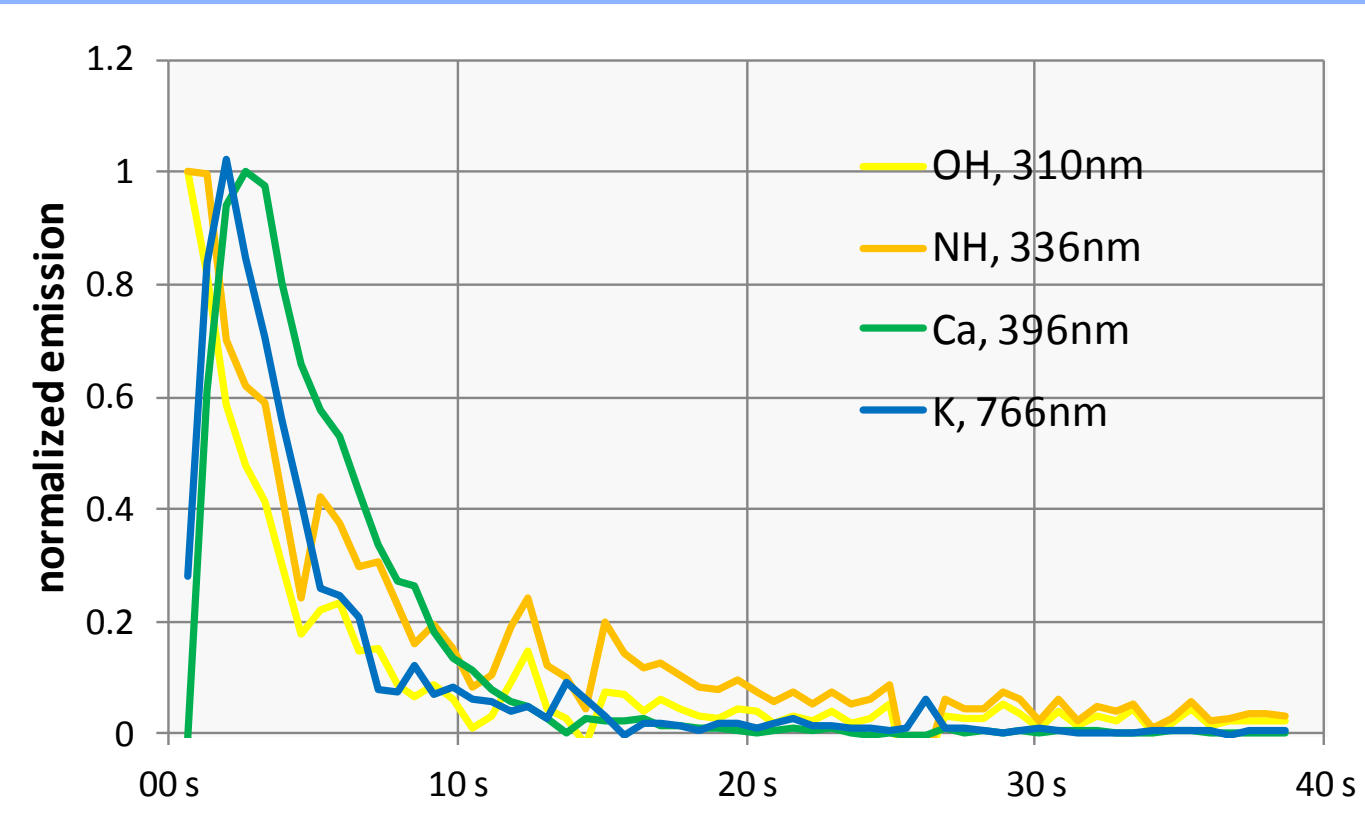

Conclusions:

time since insertion, $s$

- The ablation products $\mathrm{OH}, \mathrm{NH}$, and $\mathrm{CN}$ were seen in emission from the post shock/boundary layer

- Further characterization (e.g. for $\mathrm{CH}$ ) requires experiments in higher spectral resolution.

- The role of $\mathrm{K}$ and $\mathrm{Na}$ as strong atom emissions is still to be verified, $\mathrm{H}$ was not identified.

D. Empey, K. Skokova, P. Agrawal, G. Swanson, D. Prabhu, K. Peterson, M. Winter, E. Venkatapathy, Small Probe Reentry Investigation 